\title{
Low ligation of the inferior mesenteric artery with apical lymph-node dissection during rectosigmoid resection for preservation of the left colic artery
}

\author{
K. Guidolin ${ }^{1,2,3}$ (D) S. A. Chadi ${ }^{1,4} \cdot$ F. A. Quereshy ${ }^{1,4,5}$
}

Received: 3 July 2020 / Accepted: 12 July 2020 / Published online: 23 July 2020

(c) Springer Nature Switzerland AG 2020

The level of ligation of the inferior mesenteric artery during rectosigmoid resection has been discussed in the literature over the past few years. A high ligation (at the origin from the aorta) has the benefit of a high lymph-node yield, while a low ligation (preserving the left colic artery) can increase blood flow to a colorectal anastomosis, but may leave involved lymph nodes in situ. A compromise between these techniques has been described, wherein a low ligation is paired with a dissection of the apical inferior mesenteric artery and para-aortic lymph nodes. We demonstrate and explain this technique in our video presentation.

Electronic supplementary material The online version of this article (https://doi.org/10.1007/s10151-020-02306-6) contains supplementary material, which is available to authorized users.

F. A. Quereshy

fayez.quereshy@uhn.ca

1 Department of Surgery, University of Toronto, Toronto, Canada

2 Institute of Biomedical Engineering, University of Toronto, Toronto, Canada

3 Princess Margaret Cancer Centre, Toronto, Canada

4 Department of Surgery, University Health Network, Toronto, Canada

5 Toronto Western Hospital, Main Pavilion 8-320, 399 Bathurst Street, Toronto, ON M5T2S8, Canada

\section{Compliance with ethical standards}

Conflict of interest The authors declare that they have no conflict of interest.

Ethical approval All procedures performed in studies involving human participants were in accordance with the ethical standards of the institutional research committee and with the 1964 Helsinki Declaration and its later amendments or comparable ethical standards.

Informed consent Informed consent was obtained from all individual participants included in the study.

Publisher's Note Springer Nature remains neutral with regard to jurisdictional claims in published maps and institutional affiliations. 